(2) Open Access Full Text Article

\title{
Awareness of Health Professionals on COVID-19 and Factors Affecting It Before and During Index Case in North Shoa Zone, Ethiopia, 2020
}

\author{
Ayele Abebe (D) \\ Abinet Mekuria $\mathbb{( D}^{2}$ \\ Awraris Balchut $\mathbb{D D}^{2}$ \\ 'Department of Pediatrics Nursing, \\ Debre Berhan University, Amhara, \\ Ethiopia; ${ }^{2}$ Public Health Department, \\ Debre Berhan University, Amhara, \\ Ethiopia
}

This article was published in the following Dove Press journal: Infection and Drug Resistance

Background: COVID-19 is a disease caused by a SARS-COV2. The main way of transmission is from person to person through droplet nuclei. In this time, this disease has no treatment and vaccination. Hence, the WHO recommends countries to work intensively on prevention and control measures.

Objective: This study aimed to assess the level of awareness on clinical and epidemiological spectrum of COVID-19 and factors affecting it in the North Shoa zone, Amhara Regional State, Ethiopia, 2020.

Methods: A facility-based cross-sectional study design was used to assess awareness of health professionals on COVID-19 and associated factors affecting it before and during index case. A total of 384 participants selected from 10 hospitals participated in this study. The data were entered and coded using EPI-INFO version 3.5.4 and then transferred to SPSS version 20 for analysis. Bivariable and multivariable logistic regression were computed. Variables with a p-value less than 0.05 were taken as predictor variables.

Results: A total of 384 respondents with a response rate of $91 \%$ participated in this study. The proportion of participants with an awareness of COVID-19 was 305 (79.4\%). The types of profession $(\mathrm{AOR}=6.9,95 \% \mathrm{CI}=1.6-29.8)$ and level of a profession $(\mathrm{AOR}=2.3,95 \%$ $\mathrm{CI}=1.4-4.4)$ of the profession, availability of television at home $(\mathrm{AOR}=2.1,95 \% \mathrm{CI}=1.1$, 3.9 ) and hearing of the emerging diseases in the past ( $\mathrm{AOR}=2.7,95 \% \mathrm{CI}=1.5-5$ ) were factors that determine the awareness of health professionals on COVID-19 clinical and epidemiological spectrum.

Conclusion and Recommendations: The level of the health professional's awareness on the clinical and epidemiological spectrum of COVID-19 was promising. There is a need for a coordinated effort from stakeholders and health professionals to increase awareness.

Keywords: health professionals, factors affecting, coronavirus

\section{Introduction}

COVID-19 is a disease caused by a new strain of the coronavirus, SARS COV-2. ${ }^{1-3}$ Coronaviruses have the potential to cause severe transmissible human disease. ${ }^{4}$ Coronaviruses cause illness ranging from the common cold to more severe diseases respiratory tracts. ${ }^{1}$

The known transmission routes for coronaviruses include sustained human-tohuman transmission via respiratory, by touching a contaminated surface or objects. ${ }^{5}$ One of the challenges of COVID-19 outbreaks is that it is difficult to differentiate from other respiratory illnesses. ${ }^{6}$
Correspondence: Ayele Abebe Department of Pediatrics Nursing, Debre Berhan University, Amhara, Ethiopia Tel +251925318370

Email ayelemamol2@gmail.com
Infection and Drug Resistance 2020:1 3 2979-2988 
COVID-19 affects all people especially older age, with chronic medical conditions, such as diabetes and heart disease were at a greater risk of developing severe symptoms. ${ }^{3}$ Since 31 December 2019 and as of 23 April 2020, globally 2588068 cases of COVID-19 have been reported, including 182808 deaths. In Africa, 25,686 COVID-19 cases and 1232 deaths were reported since April 23, 2020. African countries with the highest estimated numbers of COVID-19 cases were South Africa, Egypt, Morocco, Algeria, and Cameroon. Ethiopia reported 116 COVID-19 cases and 3 deaths with 61 cases in these 14 days as of April 23, 2020. ${ }^{7}$

The COVID-19 has effect on the entire world economy including Africa. ${ }^{8}$ Examples of this include tourism, air transport, and the oil sector. Based on Africa Centers for Disease Control and Prevention (Africa CDC), 43 African countries have reported COVID-19 cases so far. The incidence of both infectious and non-communicable diseases such as chronic obstructive pulmonary disease (COPD) or asthma is high in Africa which is most vulnerable to the coronavirus, for whom the virus is often fatal. ${ }^{9}$

Ethiopia confirmed the first case of COVID-19 on March 13, 2020. Ethiopia reported a total of 116 COVID_19 cases and 3 deaths with 61 cases in these 14 days as of April 23, 2020. ${ }^{10}$ Pandemic and newly emerging infectious diseases strike developing countries including Ethiopia beyond the health system. To prevent and control newly emerging infectious diseases including COVID-19; there was a need for increased awareness, skill, and attitude of a health professional. As COVID-19 was a newly emerging pandemic disease globally, assessment of the health professionals' awareness towards clinical and epidemiological spectrum and factors influencing it was a very important agenda.

Many COVID-19 cases fully had recovery. But minority of its cases had been developed acute respiratory distress syndrome (ARDS), multiple organ failure, and sometimes death. The ratio of case-fatality is currently unknown but is estimated to be within the range of $0.5-4 \% .^{11}$

The impact of COVID-19 to all human beings is inevitable. For example, the proportions of hypertension, cardio-cerebrovascular disease, and diabetes patient with COVID-19 were $17.1 \%, 16.4 \%$, and $9.7 \%$, respectively. ${ }^{12}$ The incidences of hypertension, cardio-cerebrovascular diseases, and diabetes were about twofold upper in health care facilities. ${ }^{13,14}$ The COVID-19 virus has many dimensional negative impact on the world. ${ }^{15,16}$
The most common symptoms were fever and cough. ${ }^{18}$ Most cases have mild disease and $20 \%$ cases progress to severe respiratory diseases, and in some cases death. ${ }^{6,19,20}$

Currently, the diagnosis of COVID-19 is based on gene detection via real-time RT-PCR. With the isolation of the causative agent, the development of serological tests and rapid diagnostic tests in addition to virus detection will be required. ${ }^{21}$ In addition to the PCR test, X-ray and CTimages can be used as a suggestive diagnostic modality. ${ }^{18}$

On the other hand, scientists around the world are actively exploring drugs but efficacy and safety of these candidate drugs in the treatment of COVID-19 need to be confirmed in further preclinical and clinical trials. ${ }^{22}$ Still, there is no drug treatment or vaccine for this disease except supportive care. ${ }^{23}$

Once an individual gets sick with COVID-19, CDC recommends staying home, separate himself from other people, wear a facemask, avoid sharing personal household items and monitor symptoms. ${ }^{24-26}$ In most scenarios, highly effective contact tracing and case isolation are best for the prevention and control of COVID-19. Therefore, isolation and contact tracing decreased transmission by a decrease in the effective reproduction number. ${ }^{27}$

The Hospitals were also safeguarded by their staff who care for patients and monitoring them for signs or symptoms of infection. Hence, support is provided to the morale and well-being of the workforce. ${ }^{28}$

The experience of Hangzhou on the prevention and control of COVID-19 showed that awareness creation, contact minimization, and travel restriction were the most pertinent measures for its prevention and control. ${ }^{29}$

Different countries were following potential policies towards COVID-19 prevention and control with regards to patients, visitors, and health care workers. These were screening all visitors for any respiratory symptoms, restricting health care workers from working if they have any upper respiratory tract symptoms and screening all patients with signs and symptoms. ${ }^{30-32}$ In some countries, work from the home arrangement for some employee was also made due to the COVID-19 related closure. ${ }^{33}$ The effect of COVID-19 on developing countries is in all aspects of the globe people. This negative impact COVID-19 is very high in African country including Ethiopia. So, this study was aimed to assess the level of awareness (clinical and epidemiological spectrum) and factors related to it among health care professionals, North Shoa Zone, Ethiopia. 


\section{Methods}

\section{Study Design}

A facility-based cross-sectional study was carried out to identify the level of awareness (clinical and epidemiological spectrum) of COVID-19 and factors affecting it among health professionals at governmental public health hospitals in the North Shoa zone, Ethiopia.

\section{Study Area and Period}

The study was conducted in North Shoa Zone, Amhara regional state. This zone is found in the Amhara National Regional State. A study has been conducted from March 7-16/2020. The Zone has located $130 \mathrm{~km}$ from Addis Ababa. Regarding the health facilities there are 10 public hospitals from which 9 primary public hospital and one referral hospital, there are 97 health centers, 389 health posts in the Zone.

\section{Source Population}

Health professionals who worked in North Shoa zone government hospitals.

\section{Study Population}

Health professionals who worked in North Shoa zone government hospitals.

\section{Inclusion and Exclusion Criteria}

All health professionals who were working in the selected hospitals with a professional level of the diploma and above included in this study. Health professionals who were unable to talk, seriously ill, and recruited less than six months of duration were excluded from this study.

\section{Sample Size and Sampling Procedure Sample Size}

The sample size was calculated using a single population proportion formula as follows with a $95 \%$ confidence level, and marginal of error $5 \%$.

$$
\mathrm{n}=\mathrm{Z}(\alpha / 2)^{2} \mathrm{p}(1-\mathrm{p}) / \mathrm{d}^{2}
$$

where $\mathrm{n}=$ minimum sample size;

$\mathrm{Z}(\alpha / 2)^{2}=95 \%$ Confidence level;

$\mathrm{P}=$ proportion of awareness of COVID-19 among health professional in which $\mathrm{p}=50 \%$ since there is no previous study;

$\mathrm{D}=5 \%$ margin of error.

In which $\mathrm{n}=\left[(1.96)^{2}(0.5)(1-0.5)\right] /(0.05)^{2}=384$ adding $10 \%$ non-response rate; $n=422$.

\section{Sampling Technique and Procedure}

A total of 10 hospitals were found in the North Shoa zone, of which 9 are district hospitals, and one is referral hospital. As the two district hospitals started to provide the service recently and a few staff available (Molle and Mida Hospital), not included in the study. The remaining 8 hospitals were included in the study and a proportional to size allocation was used to collect the data (Figure 1).

\section{Data Collection Methods}

A structured questionnaire prepared in English and then translated to Amharic and back to English to maintain tool consistency. Seven physicians and one BSC nurse were assigned as data collectors and supervised by the principal. The data collection tool was pre-tested in private hospitals with a similar setup to sort out language barriers and contextual differences. Hence, any ambiguity in the questionnaires was corrected for the final data collection.

\section{Data Quality Assurance}

Questionnaires were checked and pre-test in a private hospital on $5 \%$ of participants. Principal investigators were checked for consistency and completeness to maintain the quality of data. Also, one-day training on data collection techniques and briefing of the questioners were made by the principal investigators.

\section{Data Processing and Analysis}

Data were entered, coded, and cleaned by using EPI-INFO version 3.5.4 software, and then the cleaned data were exported to SPSS version 20 software for analysis. Descriptive analysis (text, percent, mean and median) was used to describe the study population concerning relevant variables. Variable having a p-value less than 0.05 with Bivariable analysis were transferred into the multivariable analysis. Variables with a p-value of less than 0.05 in the final model were considered as statistically significant. Levels of the association were reported using AOR and a $95 \%$ confidence interval.

\section{Operation Definition}

COVID-19 awareness - health professional was considered aware of COVID-19 in its different spectrum if they score the mean value and above from 20 questions.

A spectrum of COVID-19 - the spectrum of COVID19 refers to knowing the epidemiology, risk factor, sign and symptom, diagnostic approach, management, 


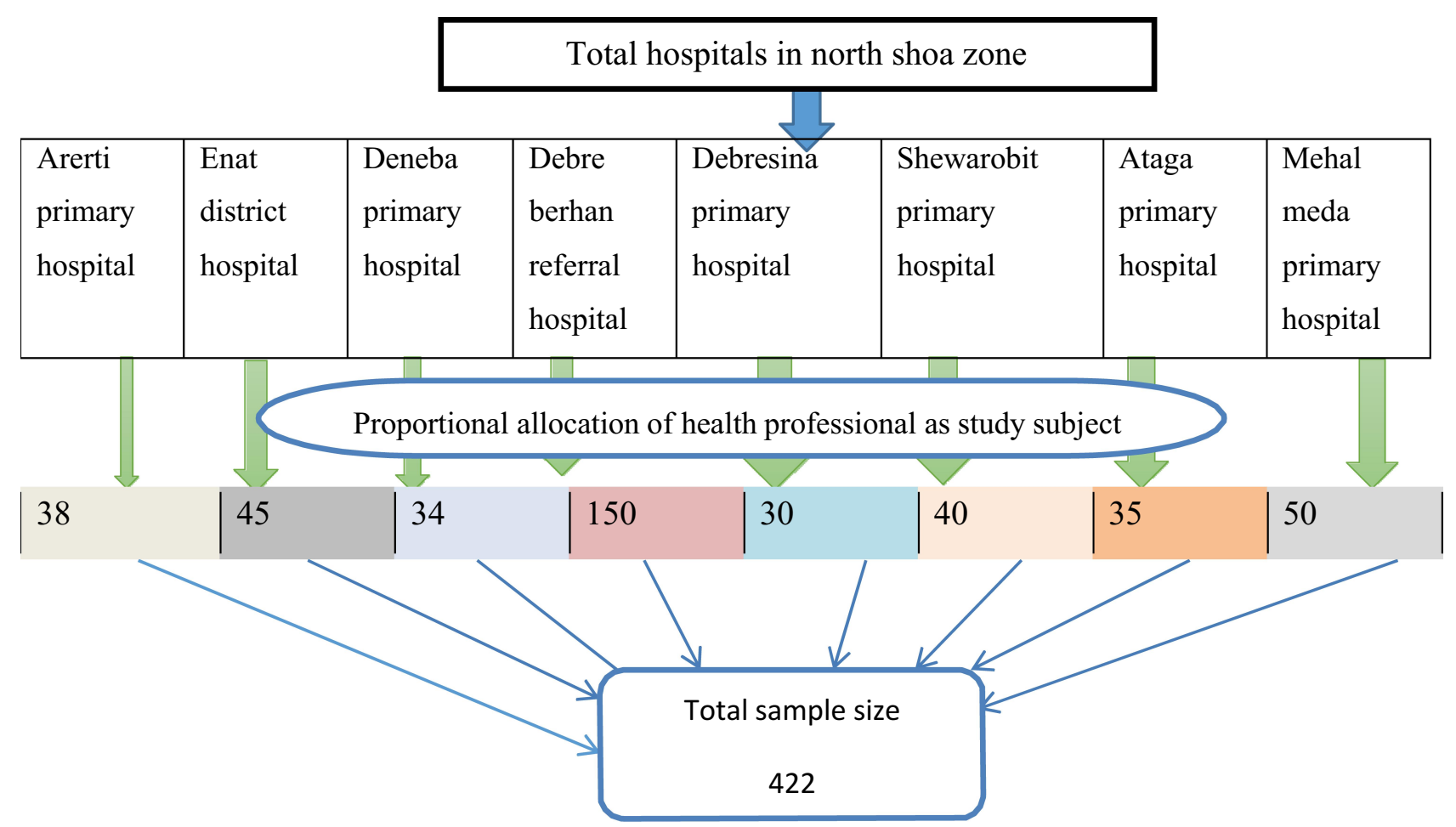

Figure I Sampling procedure on study subjects of COVID-19 awareness study at North Shoa zone among health professionals, 2020.

prevention, and control plus countries' experience to control and prevent COVID-19.

\section{Result}

\section{Socio-Demographic Characteristics of} the Respondents

A total of 384 respondents with a response rate of $91 \%$ participated in the study. About 117 (30.5\%) of the participants were from Debre Berhan referral hospital. Regarding the age distribution of the participants, 237 (61.7\%) of the participants were in the age group 26-35 years with the mean age of 28.8 years.

While in case of marital status $198(50.8 \%)$ were single. Two hundred thirty-three $(60.7 \%)$ of the participants were male. Most of the respondents 283 (73.7\%) were degree by profession. One hundred thirty-eight $(35.9 \%)$ of the respondents were worked for five and more years. About 135 (35.2\%) and 118 (30.7\%) were from Ward and OPD, respectively (Table 1).

\section{Health Professionals and Organizational Characteristics}

Majority $262(68.2 \%)$ of the participants had a television at home while 159 (41.4\%) had a radio. About 85\% (324) of the participants had a smartphone and three-fourth (298) of them did have a habit of searching health-related information via the internet. With regard to the institution, only $154(40.1 \%)$ of the health professionals reported that their institution avail television to their department. The majority of the respondents, $233(60.7 \%)$ mentioned that their institution had internet access. Only 118 (30.7\%) of the health professionals reported as their institution has a seminar on emerging diseases (Table 2).

\section{Respondents COVID-19 Related to Awareness}

The proportion of participants who were aware of COVID19 in this study was 305 (79.4\%). Among the health professionals, who heard of emerging disease, heard about COVID-19, and said COVID-19 affects mainly respiratory system were 299 (77.9\%), 372 (96.9\%) and 379 (98.7\%) respectively. Fever (373 (97.1\%)), cough (358 (93.2\%)), and shortness of breath $(342(89.1 \%))$ were the most common mentioned sign and symptoms of COVID-19 by the health professionals. Out of 384 respondents, 291 (75.8\%) were responded as COVID-19 was a zoonotic disease. About 141 (36.7\%), 337 (87.8\%), $164(42.7 \%)$, and $40(10.4 \%)$ of health professionals explained as COVID-19 was $100 \%$ fatal, affects all segments of the population, treatable disease 
Table I Socio-Demographic Characteristics of Health Professionals in North Shoa Zone, $2020(n=384)$

\begin{tabular}{|c|c|c|}
\hline Variables & Frequency & Percent \\
\hline \multicolumn{3}{|l|}{ Institution } \\
\hline Debre Berhan Referral Hospital & 117 & 30.5 \\
\hline Mahelmeda Hospital & 57 & 14.8 \\
\hline Enat Hospital & 48 & 12.5 \\
\hline Arerti Hospital & 34 & 8.9 \\
\hline Shewarobit Hospital & 40 & 10.4 \\
\hline Ataye Hospital & 36 & 9.4 \\
\hline Debre Sina Hospital & 11 & 2.9 \\
\hline Deneba Hospital & 41 & 10.7 \\
\hline \multicolumn{3}{|l|}{ Age } \\
\hline $15-25$ & 111 & 28.9 \\
\hline $26-35$ & 237 & 61.7 \\
\hline $36-45$ & 30 & 7.8 \\
\hline $46-55$ & 6 & 1.6 \\
\hline \multicolumn{3}{|l|}{ Sex } \\
\hline Male & 233 & 60.7 \\
\hline Female & 151 & 39.3 \\
\hline \multicolumn{3}{|l|}{ Marital status } \\
\hline Single & 195 & 50.8 \\
\hline Married & 189 & 49.2 \\
\hline \multicolumn{3}{|l|}{ Profession } \\
\hline Clinician & 79 & 20.6 \\
\hline Nurse & 182 & 47.4 \\
\hline Midwife & 41 & 10.7 \\
\hline Pharmacy & 37 & 9.6 \\
\hline Laboratory & 45 & 11.7 \\
\hline \multicolumn{3}{|l|}{ Level of profession } \\
\hline Diploma & 101 & 26.3 \\
\hline Degree & 283 & 73.7 \\
\hline \multicolumn{3}{|l|}{ Experiences } \\
\hline One year & 88 & 22.9 \\
\hline Two years & 76 & 19.8 \\
\hline Three years & 57 & 14.8 \\
\hline Four years & 25 & 6.5 \\
\hline Five and greater & 138 & 35.9 \\
\hline \multicolumn{3}{|l|}{ Department working } \\
\hline Ward & 135 & 35.2 \\
\hline OPD & 118 & 30.7 \\
\hline $\mathrm{MCH}$ & 12 & 3.1 \\
\hline Labor and delivery & 39 & 10.2 \\
\hline Laboratory & 43 & 11.2 \\
\hline Pharmacy & 37 & 9.6 \\
\hline
\end{tabular}

and have vaccination, respectively. Direct contact was the most common mode of transmission for COVID-19 mentioned by health professionals (Table 3 ).
Table 2 Health Professionals and Organizational Characteristics in North Shoa Zone, $2020(n=343)$

\begin{tabular}{|c|c|c|}
\hline Variables & Frequency & Percent \\
\hline \multicolumn{3}{|l|}{ Availability of television at home } \\
\hline Yes & 262 & 68.2 \\
\hline No & 122 & 31.8 \\
\hline \multicolumn{3}{|l|}{ Availability of radio at home } \\
\hline Yes & 159 & $4 I .4$ \\
\hline No & 225 & 58.6 \\
\hline \multicolumn{3}{|l|}{ Availability of smart mobile } \\
\hline Yes & 324 & 84.4 \\
\hline No & 60 & 15.6 \\
\hline \multicolumn{3}{|l|}{$\begin{array}{l}\text { The habit of health information with } \\
\text { internet }\end{array}$} \\
\hline Yes & 298 & 77.6 \\
\hline No & 86 & 22.4 \\
\hline \multicolumn{3}{|l|}{ Internet access by the mobile } \\
\hline Yes & 161 & 41.9 \\
\hline No & 223 & 58.1 \\
\hline \multicolumn{3}{|l|}{ The habit of searching with internet } \\
\hline Yes & 179 & 46.6 \\
\hline No & 205 & 53.4 \\
\hline \multicolumn{3}{|l|}{$\begin{array}{l}\text { The institution has TV in the } \\
\text { department }\end{array}$} \\
\hline Yes & 154 & 40.1 \\
\hline No & 230 & 59.9 \\
\hline \multicolumn{3}{|l|}{ Health institution internet access } \\
\hline Yes & 233 & 60.7 \\
\hline No & 151 & 39.3 \\
\hline \multicolumn{3}{|l|}{ The habit of searching with internet } \\
\hline Yes & 225 & 58.6 \\
\hline No & 159 & $4 I .4$ \\
\hline \multicolumn{3}{|l|}{$\begin{array}{l}\text { The institution had a seminar on } \\
\text { emerging diseases }\end{array}$} \\
\hline Yes & 118 & 30.7 \\
\hline No & 266 & 69.3 \\
\hline
\end{tabular}

\section{Strategies Suggested for Early Recognition}

One hundred (26\%) of the participants were explained that isolation was one of the early recognized measures of COVID19 while 53 (13.8\%) were health promotion (Figure 2).

\section{Suspect Patient with the Coronavirus Infection}

The major reason $(94.5 \%)$ rose by the respondents for a suspect patient with the coronavirus infection were travel 
Table 3 Participants' COVID-19 Awareness with Different Components in North Shoa Zone, April $2020(n=384)$

\begin{tabular}{|c|c|c|}
\hline Variables & Frequency & Percent \\
\hline \multicolumn{3}{|l|}{ Level of awareness } \\
\hline No awareness & 79 & 20.6 \\
\hline Good awareness & 305 & 79.4 \\
\hline \multicolumn{3}{|l|}{ Heard of an emerging disease } \\
\hline Yes & 299 & 77.9 \\
\hline No & 85 & 22.1 \\
\hline \multicolumn{3}{|l|}{ Heard about COVID-19 } \\
\hline Yes & 372 & 96.9 \\
\hline No & 12 & 3.1 \\
\hline \multicolumn{3}{|l|}{ How do you hear, $n=372$} \\
\hline Through television/radio & 213 & 55.5 \\
\hline Through internet & 124 & 32.3 \\
\hline From peer/professional discussion & 35 & 9.1 \\
\hline \multicolumn{3}{|c|}{$\begin{array}{l}\text { COVID-19 affects mainly respiratory } \\
\text { system }\end{array}$} \\
\hline Yes & 379 & 98.7 \\
\hline No & 5 & 1.3 \\
\hline \multicolumn{3}{|l|}{$\begin{array}{l}\text { COVID-19 have the sign and } \\
\text { symptom }\end{array}$} \\
\hline Fever & 373 & 97.1 \\
\hline Cough & 358 & 93.2 \\
\hline Shortness of breath & 342 & 89.1 \\
\hline Deharria & 106 & 27.6 \\
\hline Vomiting & 43 & 11.2 \\
\hline \multicolumn{3}{|l|}{ COVID-19 is a zoonotic disease } \\
\hline Yes & 291 & 75.8 \\
\hline No & 93 & 24.2 \\
\hline \multicolumn{3}{|l|}{$\begin{array}{l}\text { COVID-19 is a global emerging } \\
\text { disease }\end{array}$} \\
\hline Yes & 376 & 97.9 \\
\hline No & 8 & 2.1 \\
\hline \multicolumn{3}{|l|}{ COVID- 19 is $100 \%$ fatal } \\
\hline Yes & 141 & 36.7 \\
\hline No & 243 & 63.3 \\
\hline \multicolumn{3}{|l|}{$\begin{array}{l}\text { COVID-19 affects all population } \\
\text { groups }\end{array}$} \\
\hline Yes & 337 & 87.8 \\
\hline No & 47 & 12.2 \\
\hline \multicolumn{3}{|l|}{ COVID-19 is a treatable disease } \\
\hline Yes & 164 & 42.7 \\
\hline No & 220 & 57.3 \\
\hline \multicolumn{3}{|l|}{ COVID-19 have vaccine } \\
\hline Yes & 40 & 10.4 \\
\hline No & 344 & 89.6 \\
\hline
\end{tabular}

(Continued)
Table 3 (Continued).

\begin{tabular}{|l|l|l|}
\hline Variables & Frequency & Percent \\
\hline COVID-19 mode of transmission & & \\
Air-born & 309 & 80.5 \\
Feco-oral & 121 & 31.5 \\
Vector born & 69 & 18.0 \\
Blood born & 61 & 15.9 \\
Droplet nuclei & 286 & 74.5 \\
Direct contact & 314 & 81.8 \\
\hline
\end{tabular}

to an epidemic country with fever and travel to China with fever (Figure 3).

\section{Prevention and Control Methods of the Coronavirus Infection}

Vaccination of cases, hand washing and using face mask were among the most common prevention, and control methods mentioned by the health professionals, North Shoa one,2020 $(\mathrm{n}=384)$ (Figure 4).

\section{Factors Associated with an Awareness}

The association between different independent variables and health professionals' awareness of COVID19 was assessed using a binary logistic regression model. Accordingly, working health institutions, types of profession, level of the profession, availability of television at home, availability of television in the department of the working institution, and hearing about emerging diseases in the past have a significant association with health professional awareness in crude odds' ratio.

To determine the independent effect of variables on health professional awareness, multiple logistic regression analysis was done. Here in multi-variable analysis working health institutions, types of profession, level of the profession, availability of television at home, and hearing of the emerging diseases in the past had a significant association with an awareness of health professionals on COVID-19 at 95\% CI (Table 4).

Regarding the working health institution, 103 (26.8\%) of Debre Berhan Referral Hospital was aware of COVID19. About 140 (37\%) of nurses were aware of COVID-19. Midwife health professionals were about 7 times more likely to be aware of COVID-19 than that of laboratory $(\mathrm{AOR}=6.9,95 \% \mathrm{CI}=1.6-29.8)$. Regarding the level of the profession, $63 \%$ of the study participants who were aware 


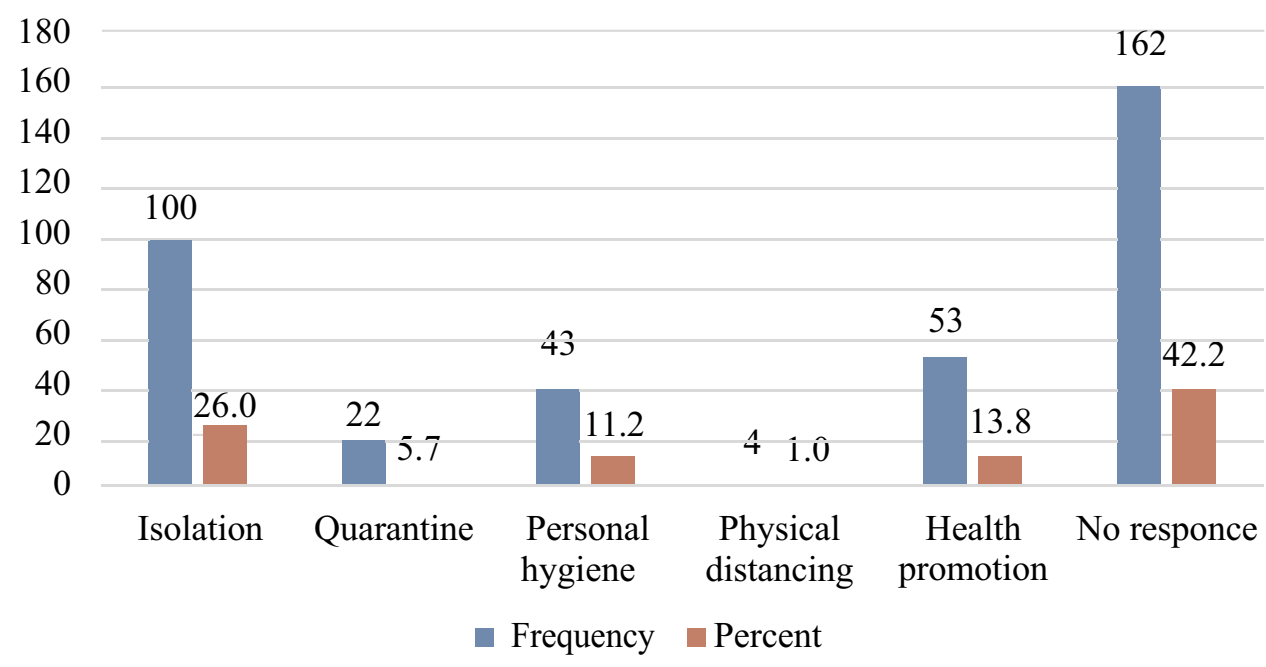

Figure 2 Strategies suggested for early recognition of COVID-19, $2020(n=384)$.

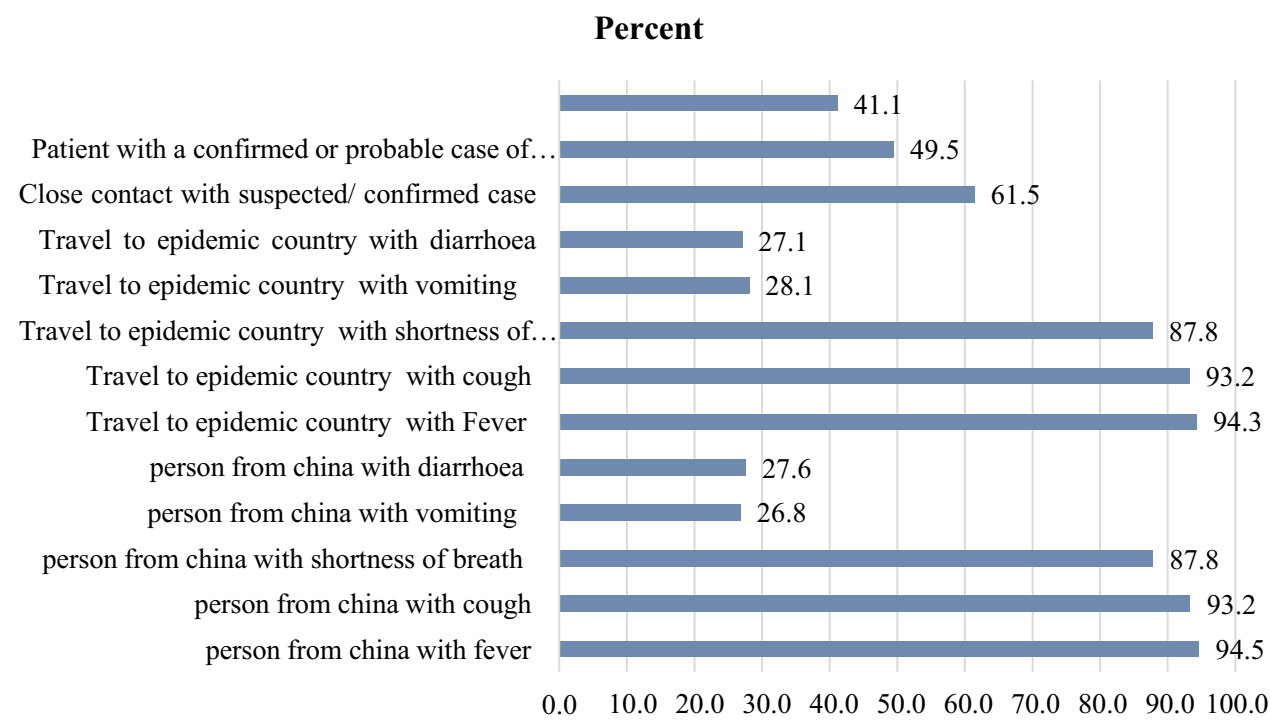

Figure 3 Suspect patient with coronavirus infection suggested by the health professionals, North Shoa zone, 2020 ( $n=384)$.

had degree level of education. Health professionals with a degree level of education were two times more likely to be aware than that of a diploma level ( $\mathrm{AOR}=2.3,95 \%$ $\mathrm{CI}=1.4-4.4)$. (Table 4)

More than half of the respondents 216 (56.3\%) who had a television at their home were aware of COVID-19. Health professionals who had a television at home were two times more aware of COVID-19 than their counterparts. Similarly, health professionals who had heard about emerging diseases were 2,7 times more likely to be aware of COVID-19 than who did not hear (AOR=2.7, 95\% $\mathrm{CI}=1.5-5)$. (Table 4)

\section{Discussion}

According to this study, the proportion of participants who were aware of COVID-19 was 305 (79.4\%) while according to the WHO recommendations, health professionals were expected to be aware and competent in medical screening and management, including health monitoring. ${ }^{34}$ The possible reason for $20 \%$ of health professionals not to be aware might be the data were collected before Covid-19 cases reported in Ethiopia.

Among the health professionals, heard about COVID19 and said COVID-19 affects mainly respiratory system was $372(96.9 \%)$ and $379(98.7 \%)$ respectively. This 


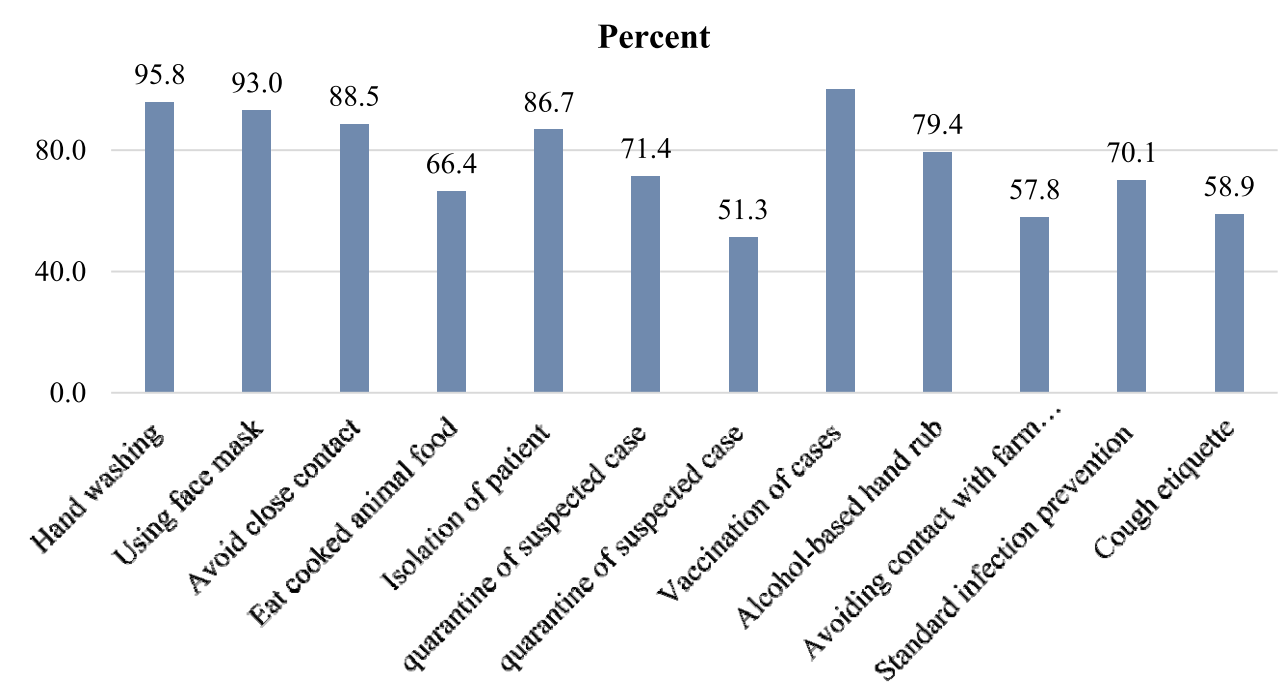

Figure 4 Prevention and control methods of coronavirus infection suggested by the health professionals, North Shoa zone, 2020 ( $\mathrm{n}=384$ ).

means most of the health professionals explain the organ most affected by the COVID-19 in line with the WHO. ${ }^{34}$

In case of sign and symptom; fever 373 (97.1\%), cough $358(93.2 \%)$ and shortness of breath 342 (89.1\%) were the most common mentioned sign and symptoms of COVID19 by the health professionals while studies and guidelines show that COVID-19 cases had a runny nose, sore throat, a cough, and fever. ${ }^{1,2,6,17}$ Out of 384 respondents, 291
(75.8\%) were responded as COVID-19 is a zoonotic disease.

Based on this study, $141(36.7 \%)$ of health professionals explained as COVID-19 is $100 \%$ fatal while studies and guidelines show that the outcomes and prognosis of COVID-19 accounts vast most cases had cured. On the other hand, COVID-19 has been rapid progression to acute respiratory distress syndrome (ARDS), multiple organs

Table 4 Bivariate and Multivariable Analysis of Factors Associated with Health Professionals' Awareness in North Shoa Zone, 2020 $(\mathrm{N}=384)$

\begin{tabular}{|c|c|c|c|c|}
\hline Factors & No awareness & Awareness & COR & AOR \\
\hline \multicolumn{5}{|l|}{ Profession } \\
\hline Clinician & $10(2.6 \%)$ & $69(18 \%))$ & $2.5(I, 6.4)$ & $1.3(0.4,3.8)$ \\
\hline Nurse & $42(10.9 \%)$ & 140 (36.5\%) & $1.2(0.6,2.6)$ & $0.8(0.4,1.9)$ \\
\hline Midwife & $3(0.8 \%)$ & $38(9.9 \%)$ & $4.6(1.2,17.7)$ & $6.9(1.6,29.8)$ \\
\hline Pharmacy & $12(3.1 \%)$ & $25(6.5 \%)$ & $0.8(0.3,2)$ & $0.9(0.3,2.8)$ \\
\hline Laboratory & $12(3.1 \%)$ & $33(8.6 \%)$ & I & I \\
\hline \multicolumn{5}{|l|}{ Level of profession } \\
\hline Diploma & 36 (9.4\%) & $65(16.9 \%)$ & 1 & 1.0 \\
\hline Degree & 43 (II.2\%) & $240(62.5 \%)$ & $3.1(1.8,5.2)$ & $2.3(1.2,4.4)$ \\
\hline \multicolumn{5}{|l|}{ Availability of TV at home } \\
\hline Yes & 46 (12\%) & $216(56.3 \%)$ & $1.7(1,2.9)$ & $2.1(1.1,3.9)$ \\
\hline No & $33(8.6 \%)$ & $89(23.2 \%)$ & 1 & I \\
\hline \multicolumn{5}{|l|}{ The institution has TV in the department } \\
\hline Yes & $24(6.3 \%)$ & $130(33.9 \%)$ & $1.7(1,2.8)$ & $1.5(0.9,2.8)$ \\
\hline No & $55(14.3 \%)$ & $175(45.6 \%)$ & 1 & I \\
\hline \multicolumn{5}{|l|}{ Heard of emerging diseases } \\
\hline Yes & $48(12.5 \%)$ & $25 I(65.4 \%)$ & $3(1.8,5.1)$ & $2.7(1.5,5)$ \\
\hline No & 31 (8.1\%) & 54 (14.1\%) & I & I \\
\hline
\end{tabular}


failure, and sometimes death in small cases. The ratio case-fatality is currently unknown but is estimated to be within the range of $0.5-4 \%$. Among the critical ills, mortality was attributed to secondary bacterial infections with multi-drug resistant organisms, sepsis, and septic shock. ${ }^{11}$

In this study, $337(87.8 \%)$ of health professionals explained as COVID-19 affects all segments of the population. Similarly, other studies showed that COVID-19 had negative impact on all segments of the population even though there was an epidemiological and clinical difference among age and co-morbid conditions. ${ }^{35,36}$

Nearly 164 (42.7\%) of health professionals explained as COVID-19 have a specific treatment while to date, there is no specific treatment for this virus. The efficacy and safety of these candidate drugs in the treatment of COVID-19 need to be confirmed in further preclinical and clinical trials. ${ }^{22}$ Supportive care, including hospitalization and intensive care unit management, was the only therapeutic option. Furthermore, the possibility that pneumonia caused by SARS-CoV-2 could, like influenza, potentiate fatal bacterial secondary infections need to be urgently investigated. ${ }^{23}$ About 40 (10.4\%) of health professionals explained as COVID-19 have vaccination while studies and guidelines show as there was no currently approved vaccine. ${ }^{23}$ Direct contact is the most common mode of transmission for COVID-19 mentioned by health professionals.

In the case of independent factors associated with an awareness were the level of a profession in which about $63 \%$ of the study participants who were aware were degree while health professionals with a degree level of education were two times more likely to be aware than that of Diploma $(\mathrm{AOR}=2.3,95 \% \mathrm{CI}=1.4-4.4)$. There were no studies on the factors associated with the level of awareness to date to compare these findings.

According to this study, more than half of the respondents $(216(56.3 \%))$ who had a television at their homes were aware of COVID-19. Health professionals who had a television at home were two times more aware of COVID19 than their counterparts. Similarly, health professionals who had heard about emerging diseases were 2.7 times more likely to be aware of COVID-19 than those who did not hear $(\mathrm{AOR}=2.7,95 \% \mathrm{CI}=1.5-5)$.

The authors conclude that the level of awareness on COVID-19 by the health professionals was promising (79.4\%). The types and level of the profession, availability of television at home, and hearing of the emerging diseases in the past were factors determine the awareness of health professional on COVID-19. Based on results found in this study, the authors recommended health institutions should have a system to address the expected competency of all health professionals during the pandemic like COVID-19. The practice of seminar presentation and selflearning among health professionals at the hospital level should also be strengthened. Furthermore, the authors recommended researches on the awareness, utilization of different health promotion channels among health professionals.

\section{Limitation of the Study}

The study design was facility-based cross-sectional. So, it had its drawback (this does not show which one was come first effect or cause).

\section{Data Sharing Statement}

All data are accessed in this manuscript.

\section{Ethics Approval and Consent to Participant}

Ethical clearance gained from Debre Birhan university research committee. The study protocol was evaluated and approved by the Research Ethics Review Committee [DBUMF053009] of College of Health Sciences, Debre Berhan university. Supportive Letter gained from Zonal health office to all selected kebeles administrative office to get their cooperative letter to show for selected mother during the data collection. Each study participant adequately informed about the purpose, method and anticipated benefit and risk of the study by their data collector. Written consent was obtained from study participants. Confidentiality and privacy kept by omitting the name of the respondents during data collection procedure.

\section{Acknowledgment}

The authors would like to thank Debre Berhan University and Debre Birhan Town Health Bureau for providing sponsoring ship. All study participants are thankful for their cooperation during sample collection.

\section{Author Contributions}

All authors contributed to data analysis, drafting or revising the article, have agreed on the journal to which the article will be submitted, gave final approval of the version to be published, and agree to be accountable for all aspects of the work. 


\section{Funding}

There is no funding to report.

\section{Disclosure}

The authors declare that they have no competing interests.

\section{References}

1. WHO. What is novel coronavirus; frequently asked questions. 2019.

2. CDC. What you need to know about 2019 novel coronavirus (2019-nCoV). 2020

3. African Union. UNICEF_school_guidance_COVID19_V5_English_ 7 pm Monday 23 March. 2020.

4. Bermingham A, Chand W, Brown C. Severer respiratory illness caused by a novel coronavirus-Euro-surveillance. 2012.

5. U. S. Government CDC. COVID - 19 response plan. 2020.

6. CDNA. Coronavirus disease 2019 (COVID-19) outbreaks in residential care facilities. 2020.

7. European Centre for Disease Prevention and Control. COVID-19 situational report. 2020.

8. African Union. Impact of the coronavirus COVID-19 on the African economy African union report. April, 2020.

9. COVID-19 in Africa: a call for coordinated governance, improved health structures, and better data. 2020 .

10. FMOH. Rapid evidence synthesis on COVID-19 pandemic to inform the Ethiopian Ministry of Health (MoH). 2020.

11. Anderson D. Clinical management of suspected or confirmed COVID-19 disease. 2020.

12. Li B, Yang J, Zhao F, et al. Prevalence and impact of cardiovascular metabolic diseases on COVID-19 in China. Clin Res Cardiol. 2020;109(5):531-538. doi:10.1007/s00392-020-01626-9

13. America college of cardiology. COVID-19 clinical guidance for the cardiovascular care team. 2020.

14. WHO.Coronavirus disease (COVID-19). 2020.

15. Thorpe J, Loughridge J, Picton M. Estimating the potential impact of COVID-19 on the Australian economy. 2020.

16. McKibbin JM, Fernando R. The global macroeconomic impacts of COVID-19: seven scenarios. 2020.

17. WHO. Coronavirus disease (COVID-19) outbreak: rights, roles, and responsibilities of health workers, including key considerations for occupational safety and health. 2020.

18. Zhao D, Yao F, Wang L, et al. A comparative study on the clinical features of COVID-19 pneumonia to other pneumonia. Clin Infect Dis. 2020.

19. World Health Organization. Golf industry guidelines to coronavirus (COVID-19). 2020.

20. WHO. Novel coronavirus(2019-nCoV) situation report 8. 2020.
21. Kim JM, Chung YS, Jo HJ, et al. Identification of coronavirus isolated from a patient in Korea with COVID-19. Osong Public Health Res Perspect. 2020;11(1):3-7. doi:10.24171/j.phrp.2020.11. 1.02

22. Dong L, Hu S, Gao J. Discovering drugs to treat coronavirus disease 2019 (COVID-19). Drug Discov Ther. 2020;14(1):58-60. doi:10.55 82/ddt.2020.01012

23. Layne SP, Hyman JM, Morens DM, Taubenberger JK. New coronavirus outbreak: framing questions for pandemic prevention. Sci Transl Med. 2020;12(534):eabb1469. doi:10.1126/scitranslmed. abb1469

24. CDC. What to do if you are sick with coronavirus disease 2019 (COVID-19). 2020.

25. CDC. Contact transmission of COVID-19 in South Korea: novel investigation techniques for tracing contacts. Osong Public Health Res Perspect. 2020;11(1):60-63. doi:10.24171/j.phrp.2020.11.1.09

26. CDC. Interim_Guidance_for_Businesses_ and_Employers_to Plan_and_Respond_to_COVID-19. 2020.

27. Hellewell J. Feasibility of controlling COVID-19 outbreaks by isolation of cases and contacts. 2020.

28. Chopra V, Toner E, Waldhorn R, Washer L. How should U.S. hospitals prepare for coronavirus disease 2019 (COVID-19)? Ann Intern Med. 2020;172(9):621-622. doi:10.7326/M20-0907

29. Diao M, Zhang S, Chen D, Hu W. The novel coronavirus (COVID-19) infection in Hangzhou: an experience to share. Infect Control Hosp Epidemiol. 2020;1-5.

30. Boulos KMN, Geraghty EM. Geographical tracking and mapping of coronavirus disease COVID-19/severe acute respiratory syndrome coronavirus 2 (SARS-CoV-2) epidemic and associated events around the world: how 21 st century GIS technologies are supporting the global fight against outbreaks and epidemics. Int $J$ Health Geogr. 2020;19(1):8.

31. Klompas M. Coronavirus Disease 2019 (COVID-19): protecting Hospitals from the invisible. Ann Intern Med. 2020;172(9):619-620. doi:10.7326/M20-0751

32. ACHA's COVID-19 Task Force. ACHA guidelines preparing for COVID-19. 2020.

33. Murphy PD, Governor E. Guidelines for state employee leave time and staffing - COVID-19. 2020.

34. WHO Oa. IASC interim guidance on COVID-19 - focus on persons deprived of their liberty. 2020.

35. Kong I, Park Y, Woo Y, et al. Early epidemiological and clinical characteristics of 28 cases of coronavirus disease in South Korea. Osong Public Health Res Perspect. 2020;11(1):8-14. doi:10.24171/j. phrp.2020.11.1.03

36. Wang L, Shi Y, Xiao T, et al. Chinese expert consensus on the perinatal and neonatal management for the prevention and control of the 2019 novel coronavirus infection (First edition). Ann Transl Med. 2020;8(3):47. doi:10.21037/atm.2020.02.20
Infection and Drug Resistance

\section{Publish your work in this journal}

Infection and Drug Resistance is an international, peer-reviewed openaccess journal that focuses on the optimal treatment of infection (bacterial, fungal and viral) and the development and institution of preventive strategies to minimize the development and spread of resistance. The journal is specifically concerned with the epidemiology of antibiotic resistance and the mechanisms of resistance development and diffusion in both hospitals and the community. The manuscript management system is completely online and includes a very quick and fair peerreview system, which is all easy to use. Visit http://www.dovepress.com/ testimonials.php to read real quotes from published authors. 